\title{
Job Decision Latitude
}

National Cancer Institute

\section{Source}

National Cancer Institute. Job Decision Latitude. NCI Thesaurus. Code C92457.

The extent to which one can make decisions and exercise control over their work. 